\title{
RNA-binding protein HuR and the members of the miR-200 family play an unconventional role in the regulation of $c$-Jun mRNA
}

\author{
GIORGIA DEL VECCHIO, ${ }^{1,4}$ FRANCESCA DE VITO, ${ }^{1,4}$ SITA J. SAUNDERS, ${ }^{2}$ ADELE RISI, ${ }^{1}$ \\ CECILIA MANNIRONI, ${ }^{3}$ IRENE BOZZONI, ${ }^{1}$ and CARLO PRESUTTI ${ }^{1}$ \\ ${ }^{1}$ Dipartimento di Biologia e Biotecnologie, Università "Sapienza," 00185 Rome, Italy \\ ${ }^{2}$ Bioinformatics Group, Department of Computer Science, Albert-Ludwigs-University Freiburg, 79110 Freiburg, Germany \\ ${ }^{3}$ IBPM-CNR, 00185 Rome, Italy
}

\begin{abstract}
Post-transcriptional gene regulation is a fundamental step for coordinating cellular response in a variety of processes. RNA-binding proteins (RBPs) and microRNAs (miRNAs) are the most important factors responsible for this regulation. Here we report that different components of the miR-200 family are involved in c-Jun mRNA regulation with the opposite effect. While miR-200b inhibits c-Jun protein production, miR-200a tends to increase the JUN amount through a stabilization of its mRNA. This action is dependent on the presence of the RBP HuR that binds the $3^{\prime}$ UTR of $c$-Jun mRNA in a region including the mir-200a binding site. The position of the binding site is fundamental; by mutating this site, we demonstrate that the effect is not micro-RNA specific. These results indicate that miR-200a triggers a microRNA-mediated stabilization of c-Jun mRNA, promoting the binding of HuR with c-Jun mRNA. This is the first example of a positive regulation exerted by a microRNA on an important oncogene in proliferating cells.
\end{abstract}

Keywords: miRNA; HuR; mRNA stability; c-Jun

\section{INTRODUCTION}

Post-transcriptional gene regulation is crucial to maintain a fine and coordinated production of proteins necessary to the cells in a variety of processes like development, homeostasis, and disease.

To achieve this result, post-transcriptional gene expression is controlled at multiple levels: pre-mRNA splicing and maturation, mRNA stability in the nucleus, mRNA transport, editing, mRNA stability in the cytoplasm, storage, and translation (Bousquet-Antonelli et al. 2000; Mitchell and Tollervey 2000; Orphanides and Reinberg 2000). mRNA turnover and translation are very well-suited steps of control to accomplish quick changes in the pattern of expressed proteins following environmental perturbations. The most important cellular factors that modulate RNA stability and translation are noncoding RNAs, in particular microRNAs (miRNAs), and turnover and translation regulatory RNA-binding proteins (TTR-RBPs). These factors associate with specific cis elements in mRNAs to perform their activity. miRNAs are short noncoding RNAs that strongly influence gene expres-

${ }^{4}$ These authors contributed equally to this work.

Corresponding author: carlo.presutti@uniroma1.it

Article published online ahead of print. Article and publication date are at http://www.rnajournal.org/cgi/doi/10.1261/rna.057588.116. sion; according to the most recent data, 2588 mature human miRNAs have been identified and sequenced (Kozomara and Griffiths-Jones 2014). They are produced from long primary transcripts synthesized by RNA Pol II (pri-miRNA) and processed in the nucleus by "microprocessor," a complex of factors containing Drosha and DiGeorge Critical Region8 (DGCR8) ribonucleases to generate precursor miRNA (premiRNA). After its translocation to the cytoplasm by Exportin5, the pre-miRNA is cleaved by another ribonuclease, Dicer, to form a duplex RNA of $\sim 22$ nucleotides (nt). One strand is then loaded into miRNA-loaded RNA-induced silencing complex (miRISC), which comprises, among others, Argonaute proteins (for review, see Ha and Kim 2014). The activated RISC can target specific mRNAs containing, generally at the $3^{\prime}$ untranslated region, sequences complementary to miRNA. mRNA and miRNA form a partial hybrid characterized by the presence of a "seed" region (nucleotides 2-7 of the miRNA) perfectly paired between the two. The interaction of miRISC with an mRNA usually inhibits its translation and this effect is often accompanied by a decrease in the stability

(C) 2016 Del Vecchio et al. This article is distributed exclusively by the RNA Society for the first 12 months after the full-issue publication date (see http:// rnajournal.cshlp.org/site/misc/terms.xhtml). After 12 months, it is available under a Creative Commons License (Attribution-NonCommercial 4.0 International), as described at http://creativecommons.org/licenses/by-nc/4.0/. 
of the mRNA. However, it has been reported that under specific conditions, the activated RISC can also promote translation (Vasudevan et al. 2007).

There are hundreds of RBPs in the human genome; the role of most of them is still poorly understood. However, it is now clear that RBPs, together with miRNAs and probably other noncoding RNAs (ncRNAs), target mRNAs in an orchestrated way to regulate their localization, stability, and finally the amount of protein synthesized. The combination of all these effects on mRNAs is known as "post-transcriptional regulatory code" (Keene 2007). Indeed, functionally related groups of mRNAs are tagged in their coding and noncoding regions early in their lives; in this way, their subsequent destinies are organized and coordinated at the various steps of processing and expression. This complex network of interaction is beginning to be addressed in eukaryotic cells where specific techniques and procedures have been devised to examine the coordinated changes in mRNAs expression.

Among the RBPs, the highly conserved ELAV/HU family consists of four family members, including three that are predominantly cytoplasmic and neurospecific $(\mathrm{HuB} / \mathrm{Hel}-$ $\mathrm{N} 1, \mathrm{Huc}$, and $\mathrm{HuD}$ ) and one that can shuttle between nucleus and cytoplasm of all human cells, HuR/HuA/ELAVL1 (HuR from now on) (Keene 1999; Hinman and Lou 2008). HuR is involved in the regulation of cell cycle, cell migration, tumorigenesis and apoptosis; consequently the HuR expression changes in many types of cancers like breast, ovary, colon, and brain, and its increase is often associated with poor prognosis (Wang et al. 2013). HuR is also implicated in gametogenesis, cell differentiation, and stem/progenitor cell survival (Levadoux-Martin et al. 2003; Ghosh et al. 2009). In macrophages, HuR is involved in the regulation of inflammatory and angiogenic processes (Zhang et al. 2012; Lu et al. 2014)

HuR binds to mRNAs containing AU-rich element (ARE) and U-rich element (URE) (Abdelmohsen and Gorospe 2010). While these sequences are known to be destabilizing for the RNAs that contain them, the binding of HuR and $\mathrm{HuD}$ increases the stability of the target mRNAs and sometimes activates their translation (Jain et al. 1997). Thus, HuR protein appears to be one of the few RBPs found to stabilize ARE- and URE-containing mRNAs under most conditions (Simone and Keene 2013).

The exact mechanisms of stabilization have not been elucidated, but the binding of HuR to a target mRNA is believed to block the interaction of other RBPs capable of driving the mRNA to sites of decay like processing bodies or to facilitate the entering of the exosome. However, HuR also modulates the translation of several target mRNAs. In some cases, this effect is carried out through the association of HuR with $5^{\prime} \mathrm{UTR}$ internal ribosome entry site (IRES), while in some others, the effect is due to a competition between HuR and miRNAs.

In this respect, there are some important studies that analyze transcriptome-wide HuR-mRNA interactions using the PAR-CLIP technique. These results have been compared to analogous known data about miRNA-mRNA interactions to elucidate the resultant regulation (Lebedeva et al. 2011; Mukherjee et al. 2011). Preliminary results and interpretations of these data seem to indicate that when microRNA and HuR binding sites overlap or are in close proximity, the transcripts are preferentially regulated by HuR, whereas when the sites are nonoverlapping, the transcripts could be mainly regulated by miRNAs. However, these conclusions are very limited and strongly related to specific mRNAs examined.

Although HuR, as stated before, tends to increase stability/ translation of the target mRNAs, there are a few examples of HuR's repressive effect on some mRNAs. In these cases HuR could cooperate with microRNAs to repress target mRNAs through destabilization and/or inhibition of translation (Kullmann et al. 2002; Yeh et al. 2008). So the combined action of HuR and miRNAs on target mRNAs seems to be very complicated and sometimes variable on different mRNAs.

In this article, we present the complex regulation accomplished by miR-200 family microRNAs on the c-Jun mRNA and the involvement of HuR in this process. JUN protein is the main component of transcription factor AP1 that is an essential regulator of many different cellular processes. JUN is often deregulated in tumors and its coding gene, c-Jun, is considered one of the most important proto-oncogenes of the cell (Lopez-Bergami et al. 2010). We show that c-Jun mRNA is regulated in an opposite way by miR-200b with respect to miR-200a: while the first has a classic inhibitory effect on the production of JUN protein, the latter appears to enhance the stability of c-Jun mRNA and to increase the protein amount. To our knowledge this is one of the very few examples in which a microRNA is able to up-regulate both the production of the protein as well as the stability of the target mRNA. The opposite effect of miR-200a and miR-200b on the expression of such an important protein like JUN raises interesting questions about the coordinated control that miR-200 family members can carry out on the same mRNA when expressed differently (Chu et al. 2015) and the importance of this action in tumor development and progression.

\section{RESULTS}

\section{miR-200 family affects the expression of $c$-Jun proto-oncogene in an opposite way}

JUN is the main component of the dimeric AP-1 transcription factor; this complex is involved in almost all areas of eukaryotic cell behavior from cell proliferation and differentiation to stress response and apoptosis. Indeed, AP1 is activated in response to several extracellular signals, from cytokines and growth factors to stress and inflammation. Because of its central role in the cells, AP-1 is often involved in tumor progression and malignant transformation during which AP1 proteins are often deregulated by oncogenic signals (Lopez-Bergami et al. 2010). 
Despite the fact that $c$-Jun is a central player in a variety of biological processes, little is known about its post-transcriptional regulation; then according to three independent target prediction algorithms (TargetSCAN, www.targetscan.org; miRanda, www.microrna.org and PicTar pictar.mdc-berlin. de), we found that $c$-Jun mRNA has predicted seed matches in its $3^{\prime}$ untranslated region (UTR), one for miR-200a/141 and one for miR-200b/200c/429 (Fig. 1A).

In our experiments we utilized miR-200a and miR-200b as representative for the two miR-200 family functional groups. To determine whether miR-200s could target the $3^{\prime}$ UTR of c-Jun mRNA, we cotransfected a reporter construct in which

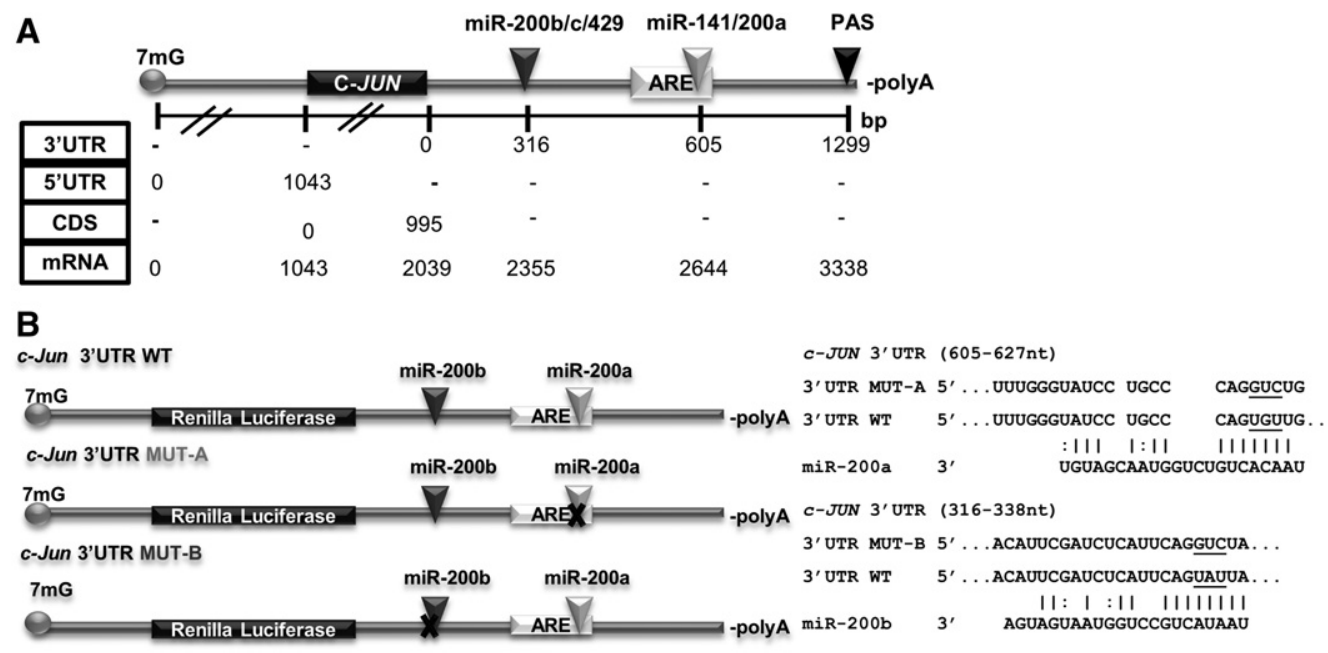

C

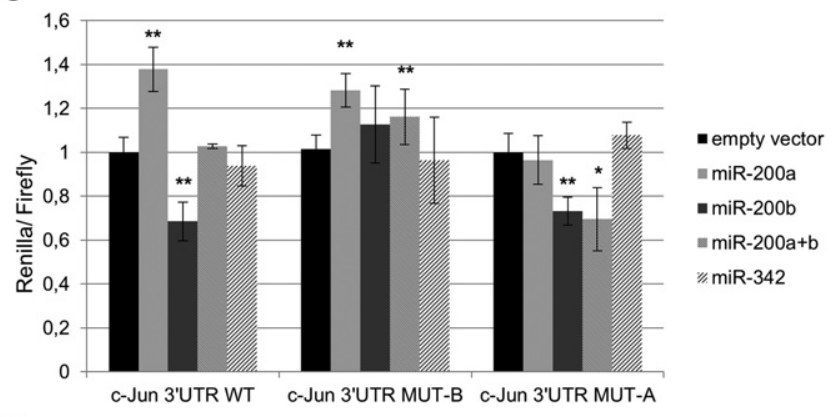

D

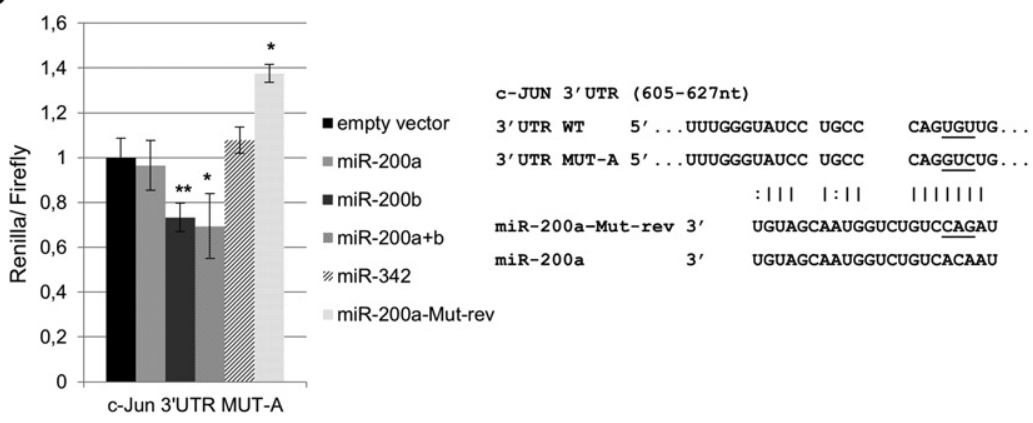

FIGURE 1. (A) Schematic of the $c$-Jun $3^{\prime}$ UTR with the location of the predicted miR-200a/14 and miR-200b/c/429 target sites. (B) Schematic of the Luciferase constructs with $c$-Jun $3^{\prime}$ UTR WT, mutants A or B (left panel) and alignment of $c$-Jun $3^{\prime}$ UTR WT or mutated (MUT-B or MUT-A) with seed region of miR-200b or miR-200a (right panel); the mutated nucleotides are underlined. (C) Luciferase assay with HEK 293T cotransfected with reporter construct (c-Jun 3'UTR WT, c-Jun 3'UTR MUT-A, c-Jun 3'UTR MUT-B) and a microRNA overexpressing plasmid (miR-200a, miR-200b, miR-342) revealed an antithetical effect of miR-200a and miR-200b on $c$-Jun $3^{\prime}$ UTR. The mean values of the corresponding empty vector were set to one. (D) Luciferase assay on HEK 293T, cotransfected with reporter construct $c$-Jun $3^{\prime}$ UTR MUT-A and microRNA overexpressing plasmids (miR-200a, miR-200b, miR-342, miR-200a-comp-mut), indicated that, in the presence of the compensatory mutation in the seed sequence of miR$200 \mathrm{a}$, the inductive effect of the miRNA on the c-Jun $3^{\prime}$ UTR is recovered. The mean value of the corresponding empty vector was set to one. Data represent the mean \pm SD and asterisks $\left(^{*}\right)$ indicate statistically significant modulations with respect to empty vector according to paired Student's test. $\left(^{*}\right) P<0.05 ;\left({ }^{*}\right) P<0.01$. 
the human c-Jun $3^{\prime}$ UTR WT was fused to Renilla Luciferase (RLuc) and a miR-200a or miR-200b expression plasmid into the HEK 293T cell line; these cells express miR-200s at a very low level. The Rluc activity was strongly repressed in cells transfected with the miR-200b overexpressing plasmid (Fig. 1C; Bracken et al. 2014; Jadhav et al. 2014), as expected from a targeting microRNA. Surprisingly, the overexpression of miR-200a increased the RLuc activity. When both miRNAs were overexpressed together the luciferase activity did not change compared to the control. In order to verify that the observed effect could be ascribed to the direct pairing between the microRNAs and the c-Jun $3^{\prime} \mathrm{UTR}$, we generated two different mutants, one for the miR-200b binding site, named mutant B (MUT-B), and one for the miR-200a binding site, named mutant A (MUT-A). The two mutants were obtained by the replacement of three nucleotides of $c$-Jun $3^{\prime}$ UTR from the second to the fourth nucleotide of miR200 seeds, with $5^{\prime}$-GUC-3' (Fig. 1B). The MUT-B 3'UTR was completely resistant to the suppressing activity of miR$200 \mathrm{~b}$ while the inductive effect of miR-200a was preserved (Fig. 1C). The opposite happened with the MUT-A 3'UTR; using this construct the inductive effect of miR-200a was lost but we were still able to observe the suppressive action of miR-200b (Fig. 1C). We also generated an overexpressing plasmid carrying the sequence for miR-200a pre-microRNA with a mutation in the seed sequence. We changed three nucleotides in the seed sequence (ACA $\rightarrow$ GAC) to allow the binding of this mutated miR-200a, named the miR-200a compensatory mutant (miR-200a-comp-mut), to the MUT-A 3'UTR. With this mutation we restored the pairing between the microRNA and the mRNA 3'UTR and recovered the inductive effect of the miRNA (Fig. 1D).

To investigate the effect of miR-200a and miR-200b overexpression also on endogenous $c$-Jun, we performed a quantitative real-time PCR (qRT-PCR) to measure the expression level of c-Jun mRNA (Fig. 2A) and a Western blot assay for the protein (Fig. 2B). We noticed that in the presence of miR-200b we obtained a reduction in both mRNA and the protein of $c$-Jun, compared to the cells transfected with the empty vector. The opposite happened when we transfected the HEK 293T cells with miR-200a overexpressing plasmid; the level of both $c$-Jun mRNA and JUN protein were increased.

Since a change in the level of $c$-Jun mRNA can be caused by either an increase in the transcription level or an alteration of mRNA stability, we further investigated the variations observed. Actinomycin D, an inhibitor of RNA polymerase II, was added to the cell culture media $24 \mathrm{~h}$ after transfection of HEK 293T cells with miR-200a overexpressing plasmid or the empty vector control. qRT-PCR performed on total mRNA, after 2, 4, and $8 \mathrm{~h}$ by the addition of actinomycin $\mathrm{D}$, showed substantial differences in c-Jun mRNA stability (Fig. 2C). Also in this condition, the overexpression of miR200a increased the c-Jun mRNA half-life up to $8 \mathrm{~h}$ with respect to the cells transfected with the empty vector where the c-Jun mRNA half-life was around $3 \mathrm{~h}$ (Fig. 2C), confirming the role of miR-200a in stabilizing c-Jun mRNA. These findings indicated an increase of about twofold in c-Jun mRNA steady state levels upon miR-200a overexpression.

Considering the increase of endogenous JUN protein, we wondered whether the AP-1 transcription complex could be affected in its functional role. In order to verify that, we transfected the not metastatic breast cancer cell line, MCF7, which expresses the miR-200 family members, with a locked nucleic acid (LNA) anti-miR-200a or miR-200b, to selectively repress the expression of miR-200a or miR-200b in order to highlight the effect of the two microRNAs individually. After $24 \mathrm{~h}$ we measured $c$-Jun mRNA quantity by qRTPCR; a scramble LNA was used as control. We observed that the mRNA level of $c$-Jun was increased in cells transfected with the anti-miR-200b inhibitor, compared to the scramble LNA and, interestingly, we observed the same effect also on matrix metallopeptidase $9(\mathrm{Mmp}-9)$ and vascular endothelial growth factor A (Vegf-A) mRNAs (Fig. 2D), which are genes transcriptionally regulated by the AP-1 complex. When we utilized the anti-miR-200a, we observed a decrease in mRNAs level, suggesting that miR-200 family members also have a role in the regulation of AP-1 complex activity, in which $c$-Jun is the central component.

Previous works have demonstrated that ZEB1 and ZEB2, which regulate the expression of the important adhesion molecule E-Cadherin, are targeted by miR-200 family members (Korpal et al. 2008; Park et al. 2008); this is the reason why this microRNA family is often associated with the inhibition of epithelial to mesenchymal transition (EMT). Here, we checked the importance of mir-200 family action on c-Jun mRNA by monitoring the migration capability of the cells that is generally associated with metastatic competence. We transfected a metastatic breast cancer cells line, MDA-MB231, that do not express the miR-200 family, with the overexpressing plasmid for miR-200b, miR-200a or with the empty vector.

Twenty-four hours after transfection, we measured the cells' migration rate through a scratch test in the cells' monolayer. The cells transfected with the empty vector closed the scratch in $24 \mathrm{~h}$, whereas the cells transfected with the miR$200 \mathrm{~b}$ overexpressing plasmid were still maintaining the scratch after $24 \mathrm{~h}$. No differences were observed for the cells transfected with miR-200a with respect to the empty vector control (Fig. 2E). To better clarify the mechanisms by which miR-200b reduces cancer cell migration, we performed the same experiment with cells transfected with a siRNA against c-Jun (siJun) or a control siRNA (Fig. 2E). siJun transfection causes a four times reduction of JUN protein amount, in comparison to cells transfected with control siRNA (Fig. $2 \mathrm{E}$, right panel). After $24 \mathrm{~h}$ of monitoring, cells transfected with a control siRNA closed the scratch while cells transfected with siJun were still separated by the scratch (Fig. 2E). These experiments show that the miR-200b effect on the c-Jun expression is sufficient to inhibit migration of metastatic cells. 
A

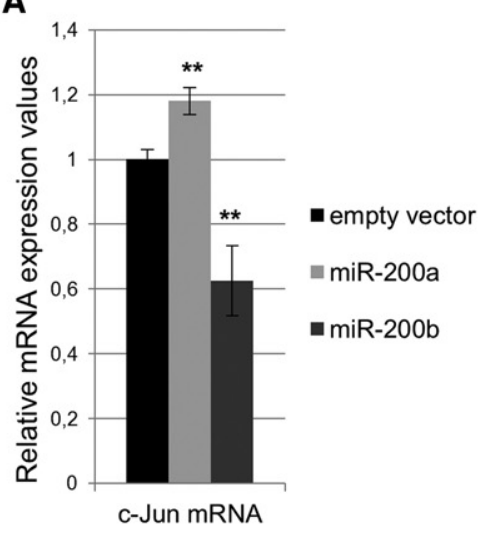

C

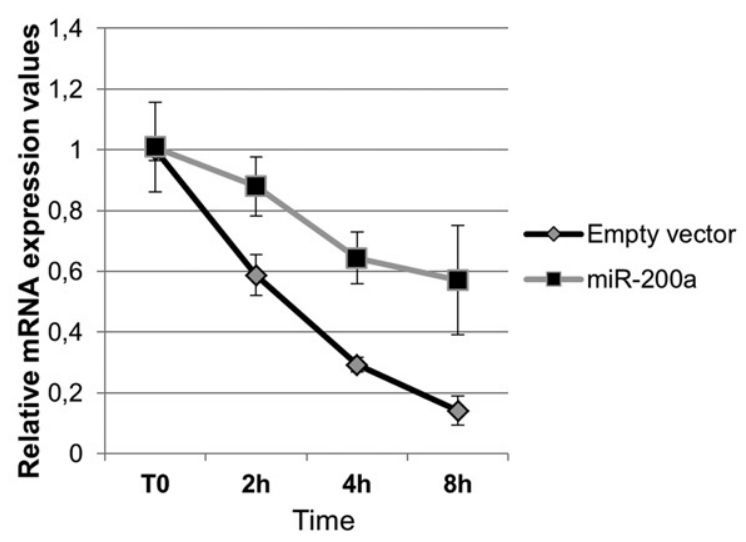

B
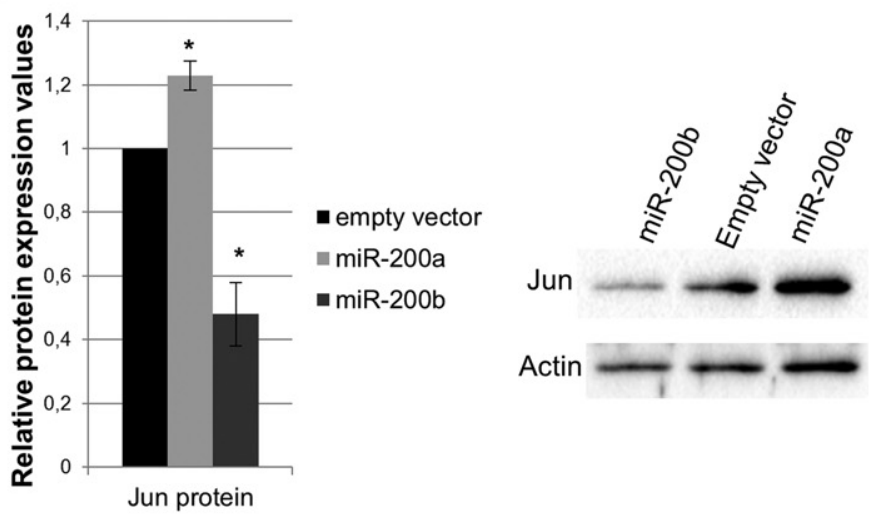

D

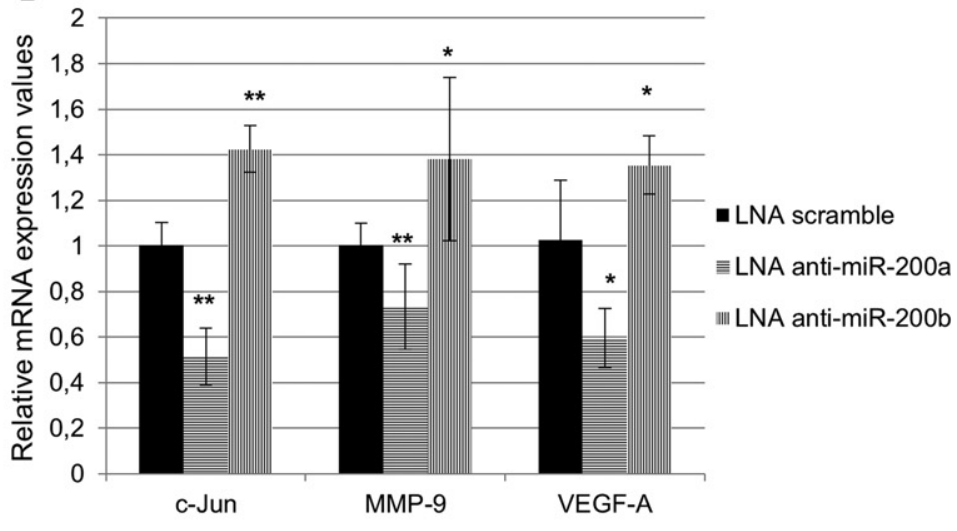

E
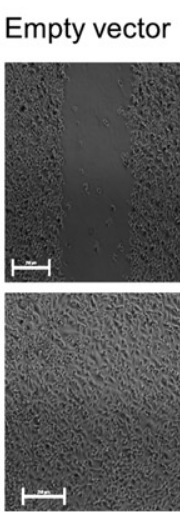

miR-200b
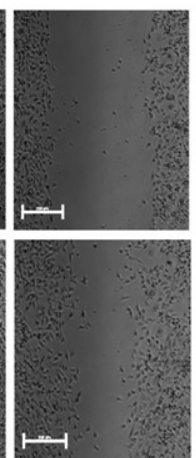

mir-200a
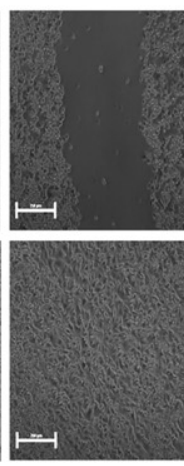

siCtr
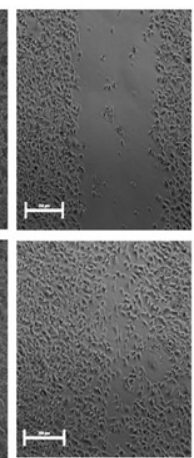

siJun

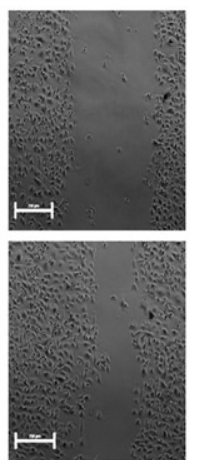

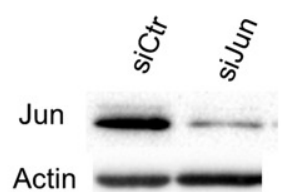

Actin

FIGURE 2. (A) qRT-PCR of $c$-Jun mRNA showed an opposite effect of the two microRNAs, miR-200a and miR-200b, on the expression level of endogenous $c$-Jun mRNA. The mean value of the corresponding empty vector was set to one, and data represent the mean \pm SD of two independent experiments. (B) JUN protein level measured by Western blotting. The graphic on the left represents the densitometry analysis of three independent experiments; on the right there is only one representative WB experiment; the empty vector was set to one. $(C)$ Inhibition of transcription by actinomycin D. HEK 293T cells were transfected with the miR-200a overexpressing plasmid or with the empty vector. Twenty-four hours after transfection, cells were treated with actinomycin D for the times indicated (bottom of the graph). Total mRNA was extracted, quantified, and analyzed by qRTPCR with primers detecting the endogenous $c$-Jun mRNA. The amount of $c$-Jun mRNA present in the cells, transfected with miR-200a overexpressing plasmid or the empty vector control, before the addition of actinomycin D was utilized as reference point and set to one. (D) qRT-PCR of $c$-Jun, matrix metallopeptidase 9 (Mmp-9), and vascular endothelial growth factor A (Vegf-A) mRNAs performed with RNA from MCF7 cells transfected with LNA microRNA inhibitor anti-miR-200a, miR-200b, or scramble. (E) (Left panel) Wound healing assay with metastatic breast cancer cells line, MDA-MB231. Cells were transfected with empty vector or miR-200b and scramble or c-Jun siRNA. Twenty-four hours after transfection we generated a scratch in the cells' monolayer, and we observed the cells migration rate hourly, for $24 \mathrm{~h}$. The white bar in the panels represents $250 \mu \mathrm{m}$. (Right panel) Western blotting evaluation of siRNA knockdown. Proteins were isolated after wound healing assay and actin serves as loading control. Data represent the mean $\pm \mathrm{SD}$, and asterisks $\left(^{*}\right)$ in all the figures indicate statistically significant modulations with respect to empty vector according to paired Student's test. $\left(^{*}\right) P<0.05 ;(* *) P<0.01$. 


\section{The noncanonical action of miR-200a is miR-binding site position specific}

We tried to understand how miR-200a could enhance the $c$ Jun expression. To explain this unconventional effect, we formulated two hypotheses: (i) miR-200a could compete with a destabilizing factor to bind the $c$-Jun $3^{\prime}$ UTR, or (ii) miR-200a could cooperate with a stabilizing factor on $c-J u n$ mRNA. We noticed that the c-Jun mRNA 3'UTR contains a well-characterized ARE sequence (Peng et al. 1998) and that the miR200a binding site is located in this sequence, so we assumed that the action of miR-200a on the reporter construct could be related to its localization in the c-Jun $3^{\prime}$ UTR (Fig. 1A).

The ARE elements are sequences rich in adenines and uracils; they are often bound by specific RNA-binding proteins (RBPs). Systematic study of several RBPs implicated in post-transcriptional gene regulation revealed that $\mathrm{HuR}$ could be a good candidate for our model. In fact, HuR is known as a stabilizer of ARE-bearing mRNAs; it is ubiquitously expressed in the cells and regulates the stability and translation of many ARE-containing mRNAs. It has been reported that HuR could bind the c-Jun mRNA 3'UTR, even if in a suboptimal way (Peng et al. 1998). In order to demonstrate that $\mathrm{HuR}$ might be involved in the post-transcriptional regulation of $c$-Jun, we performed a luciferase assay with HEK 293T cells transfected with siRNA against HuR mRNA (siHuR) or with a control siRNA. After $24 \mathrm{~h}$ the cells were cotransfected with a luciferase construct and a microRNA overexpressing plasmid, as previously described. The luciferase assay reveals that after the depletion of HuR our reporter construct was unaffected by miR-200a overexpression, but it was still influenced by the miR-200b overexpression (Fig. $3 \mathrm{~A})$. This result suggests an involvement of HuR in the noncanonical action of miR-200a.

In order to analyze the effect of siHuR also on endogenous $c$-Jun, we perform a qRT-PCR and a Western blot assay to measure the mRNA and protein levels of c-Jun (Fig. 3B,C). In cells transfected with the control siRNA (siCtr) and miR200a overexpressing plasmid, we are still able to appreciate the inductive effect on $c$-Jun mRNA and protein, mediated by miR-200a. In cells transfected with siCtr and miR-200b overexpressing plasmid, we obtained a reduction in $c$-Jun mRNA (Fig. 3B,C), compared with cells transfected with the empty vector, as observed before (Fig. 2A,B). When we performed the experiment with a siRNA against HuR, we confirmed the results obtained in the experiments with reporter construct (Fig. 3A). Upon HuR depletion (Fig. 3C), the miR-200b mediated reduction of the endogenous $c$-Jun was preserved while the miR-200a mediated increase was abolished (Fig. 3B,C). These results clearly suggest an involvement of $\mathrm{HuR}$ in the noncanonical effect mediated by miR-200a on c-Jun mRNA.

To determine whether miR-200a could actually enhance the binding affinity of HuR to $c$-Jun $3^{\prime} \mathrm{UTR}$, we performed an RNA immunoprecipitation (RIP) to study the association of endogenous HuR with $c$-Jun mRNAs, using cytoplasmic fractions of cells transfected with empty vector or miR200a overexpressing plasmid. When the lysate from cells overexpressing miR-200a was processed, the qRT-PCR assay revealed the enrichment of c-Jun mRNA levels in the IP sample (with anti-HuR antibody), in the presence of miR200a, relative to the IgG control (Fig. 3D). In the presence of the empty vector, we observed a similar c-Jun mRNA level in the IP sample compared to the IgG control; this result confirms that in the absence of stabilizing factors, HuR cannot bind the c-Jun ARE sequence with high affinity. As a negative control, we checked the abundance of c-Jun mRNA in only beads (OB) samples: it remained unchanged independently of miR-200a. In the input samples, we observed an increase in the endogenous level of $c$-Jun mRNA expression in the cells transfected with a miR-200a overexpressing plasmid compared to the cells transfected with the empty vector (Fig. 3E) as we previously observed (Fig. 2A). Taken together, these observations indicate that HuR is involved in the inductive action of miR-200a and that HuR associates more strongly with the $c-J u n$ mRNA after miR-200a overexpression.

Next, we decided to evaluate the importance of the microRNA binding site localization inside the $c$-Jun ARE sequence versus the specificity of the microRNA involved. In order to do that, we generated a mutant with a swap in the binding site of the members of the miR-200 family (Fig. 3F). The mutant, named c-Jun 3'UTR MUT-INV, presented the position of miR-200a and miR-200b binding sites reciprocally exchanged. We performed a luciferase assay with the c-Jun 3'UTR MUT-INV reporter construct and we found that in this new sequence rearrangement, overexpression of miR-200a induced a significant decrease in RLuc activity whereas the overexpression of miR-200b caused an increase in RLuc activity (Fig. 3G). With the 3'UTR MUT-INV we also performed a luciferase assay with a HuR siRNA, and we observed that with the depletion of HuR our reporter construct, c-Jun 3'UTR MUT-INV, was completely resistant to the inductive effect of miR-200b (Fig. 3H), as we previously observed for the c-Jun $3^{\prime} \mathrm{UTR}$ WT in the presence of miR200a (Fig. 3A). These results suggest that the noncanonical effect is HuR dependent and it is due to the localization of the microRNA binding site.

Finally, we questioned whether this noncanonical action of a microRNA could encompass other mRNAs, so we looked at mRNAs with a $3^{\prime}$ UTR organization similar to $c$-Jun. We found that Dual Specificity Phosphatase 1 (Dusp1) mRNA $3^{\prime}$ UTR contains an extended ARE sequence (Kuwano et al. 2008), and it has two binding sites for miR-200 family members, one for miR-200a/141 and one for miR-200b/200c/429, and the miR-200a binding site is again into an AU-rich element. We performed a luciferase assay in HEK 293T cells, with the reporter construct carrying the Dusp1 3'UTR, cotransfected with the microRNA overexpressing plasmids, and we obtained the same noncanonical event (Supplemental 
A

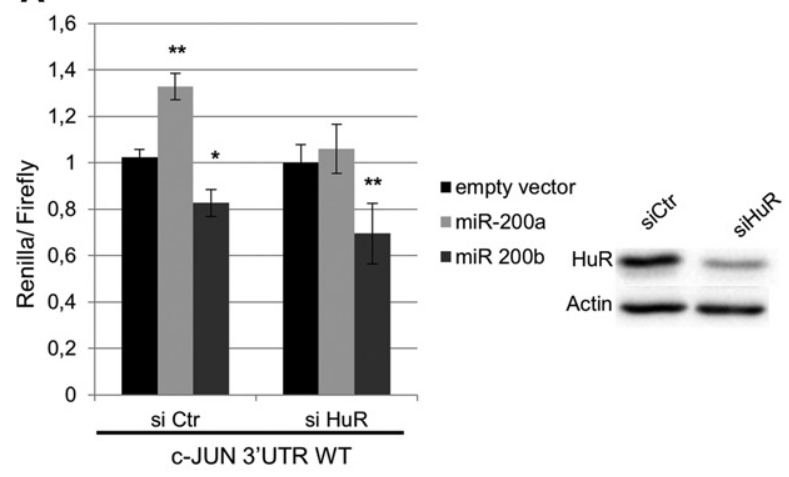

C

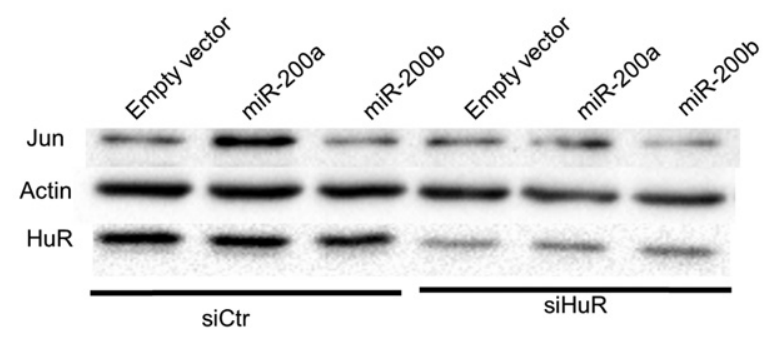

D

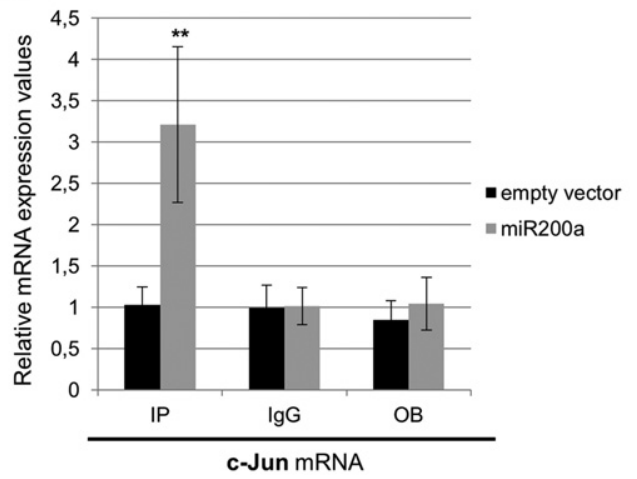

B
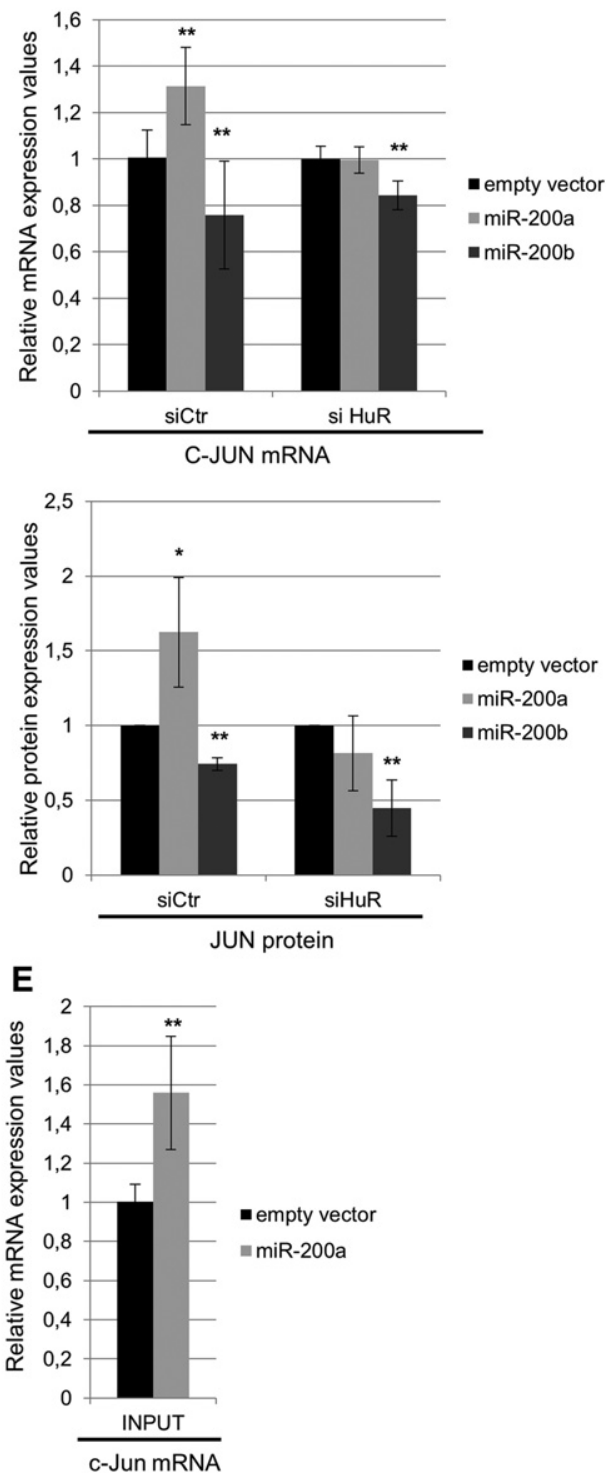

FIGURE 3. (A) (Left panel) Luciferase assay with HEK 293T cells transfected with a siHuR or a scramble siRNA (siCtr) shows that HuR is involved in the noncanonical regulation mediated by miR-200a on the $c$-Jun $3^{\prime} \mathrm{UTR}$ WT. The mean value of the corresponding empty vector was set to one. (Right panel) Western blotting evaluation of siRNA knockdown. Proteins were isolated after wound healing assay and actin serves as loading control. (B) qRT-PCR of $c$-Jun mRNA on cells transfected with the microRNAs overexpressing plasmids (miR-200a, miR-200b, empty vector) and a siRNA control (siCtr) or a siHuR. In the cells transfected with the siHuR, we completely lost the miR-200a inductive effect on $c$-Jun mRNA, suggesting an involvement of the RNA-binding HuR in the noncanonical action mediated by miR-200a. The mean value of the corresponding empty vector was set to one. $(C)$ JUN protein level measured by Western blotting. The graphic on the left represents the densitometry analysis of three independent experiments; on the right there is only one representative WB experiment; the empty vector was set to one. $(D)$ qRT-PCR with samples from RNA-immunoprecipitation assay (IP, IgG, OB) show a three times enrichment of HuR/c-Jun mRNA interaction in the presence of miR-200a. The mean value of the corresponding IgG was set to one; OB (only beads) was the negative control. (E) qRT-PCRs on input samples from the RIP assay in HEK 293T cells confirmed that $c$-Jun mRNA was more abundant in the cells transfected with the miR-200a overexpression plasmid compared to the cells transfected with the empty vector. The mean value of the corresponding empty vector was set to one. (F) Schematic of the Luciferase construct with $c$-Jun $3^{\prime} \mathrm{UTR}$ MUT-INV that contains a reciprocal exchange in the sequence bounded by the seed region of miR-200a and miR-200b. The mutated nucleotides are underlined. (G) HEK 293T transfection with reporter construct. c-Jun 3'UTR MUT-INV showed that in the new sequence rearrangement, miR-200b induced the RLuc whereas the miR-200a repressed it. The mean value of the corresponding empty vector was set to one. $(H)$ Luciferase assay performed with HEK $293 \mathrm{~T}$ cells transfected with a HuR or a scramble siRNA revealed that also with the $3^{\prime} \mathrm{UTR}$ MUT-INV there was an involvement of HuR in the noncanonical effect. The mean value of the corresponding empty vector was set to one. Data represented the mean \pm SD and asterisks $\left({ }^{*}\right)$ (in panels $\left.A-E, G, H\right)$ indicate statistically significant modulations with respect to empty vector according to paired Student's test. $\left({ }^{*}\right) P<0.05$; $\left.{ }^{* *}\right) P<0.01$. 
$\mathbf{F}$

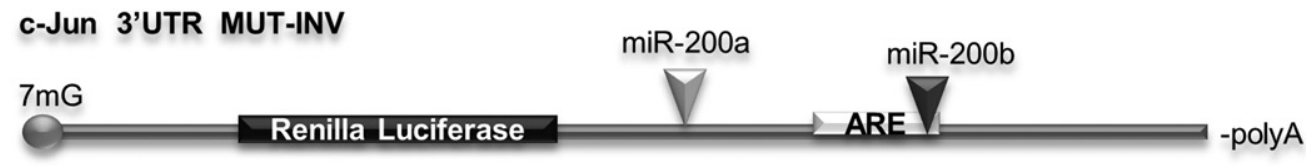

C-JUN 3'UTR (316-338nt)

3'UTR WT 5' ... ACAUUCGAUCUCAUUCAGUAUUA...

3' UTR MUT-INV 5' . . ACAUUCGAUCUCAUUCAGUGUUA... \|\|$|:|||||||||$

miR-200a 3' UGUAGCAAUGGUCUGUCACAAU

G

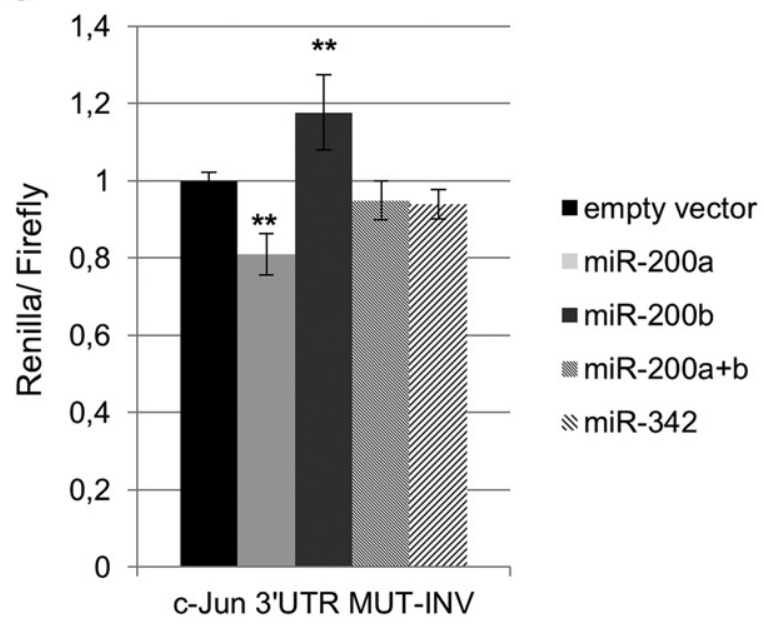

FIGURE 3. Continued.

Fig. S1). The overexpression of miR-200a increased the RLuc activity compared with the empty vector whereas miR-200b targeted the Dusp1 mRNA and the luciferase activity was repressed. With a quantitative real-time PCR we also analyzed the endogenous mRNA level of Dusp1, and we found that with the overexpression of miR-200a the mRNA level of DUSP1 was enhanced compared to the empty vector, but with miR-200b overexpression the Duspl mRNA level was decreased (Supplemental Fig. S1).

To exclude the fact that such an unusual feature of regulation could be ascribed to a specific cellular background, we repeated most of the experiments in HeLa cells with identical results (Supplemental Fig. S2).

\section{DISCUSSION}

The two most important mechanisms for regulating mRNA stability, turnover and translation are the A/U-rich elements (AREs) with their binding proteins, and microRNAs. Both these pathways are localized on conserved elements located

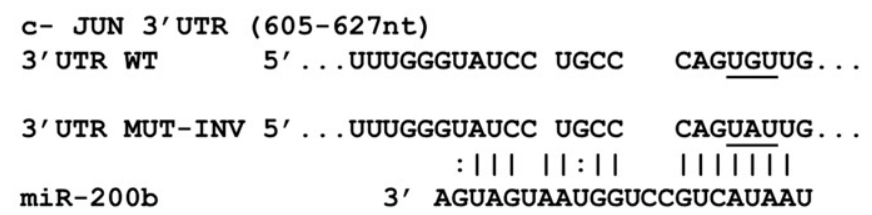

H

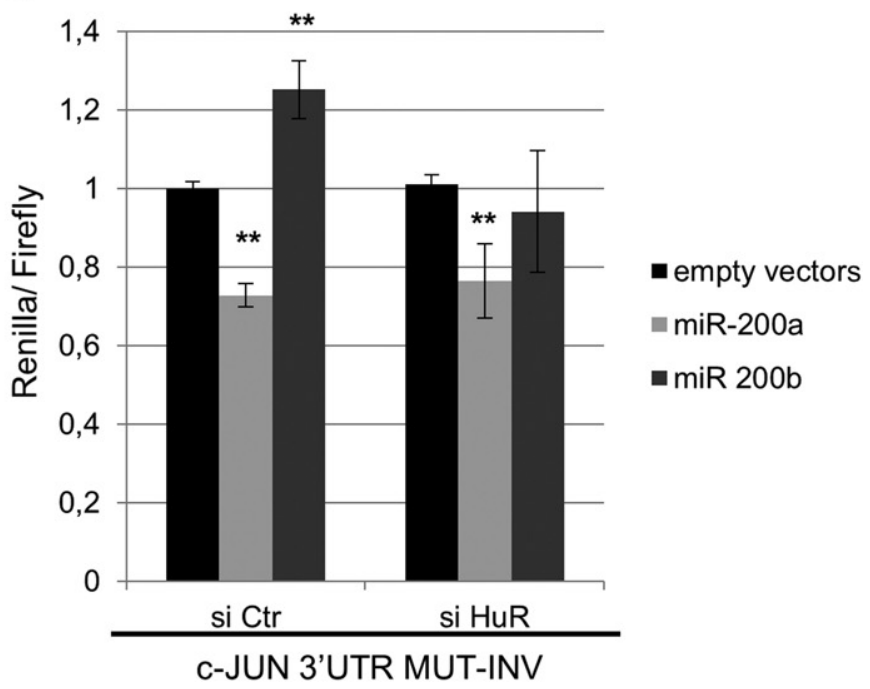

in the $3^{\prime}$ UTR of mRNAs, so it is likely the factors involved in the two processes may interact with each other. Among the ARE binding proteins, HuR plays a fundamental role in regulating the stability of mRNAs deeply involved in oncogenesis, inflammatory pathways, and stress response; so there have been many attempts to elucidate how HuR may affect mRNAs function through interactions with microRNAs. The common view is that HuR can globally repress the degradative/inhibitory effect of miRNAs on the target mRNAs, through a direct competition for the binding sites. Indeed, when binding sites for miRNAs and HuR are proximal, HuR (and probably other RBPs) can either block or displace the miRNP complex, allowing mRNA targets to be stabilized (for review, see Simone and Keene 2013). Still, there does not appear to be a single general mechanism by which HuR antagonizes miRNPs: For example, HuR has been shown to actually decrease mRNA stability and translation of c-myc mRNA by the recruiting of let- $7 \mathrm{miR}$ and RISC complex (Kim et al. 2009). On the other hand, HuR appears to positively regulate c-Myc both directly and indirectly (for review, 
A

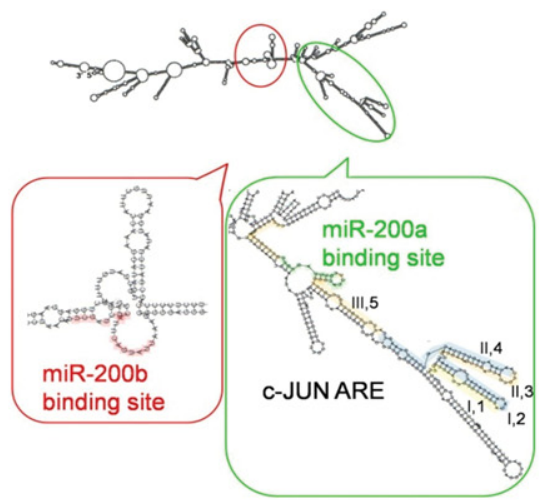

B

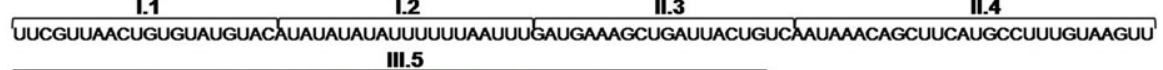
III.5

C

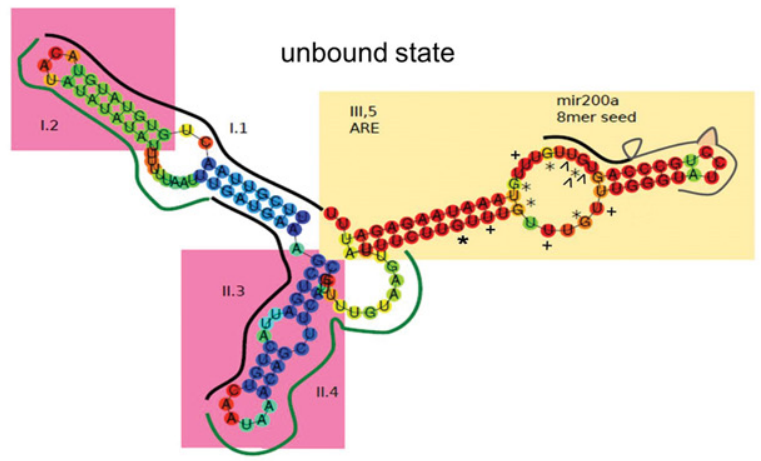

D

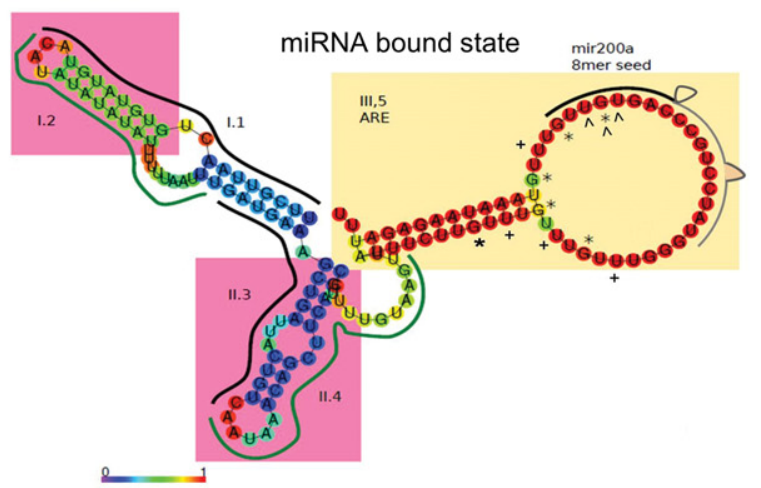

FIGURE 4. miR-200a binding may alter $c$-Jun ARE structure. (A) 2D prediction of the entire $c$-Jun $3^{\prime}$ UTR available on UCSC (energy $=-386.00 \mathrm{kcal} /$ $\mathrm{mol}$ ). miR-200b binding region is zoomed into the red box. $c$-Jun ARE-containing miR-200a binding site is in the green box. ARE domains and subdomains are reported and indicated alternatively in blue and yellow. (B) RNA sequence of the $c$-Jun ARE. miR-200a binding site is highlighted in green. $(C, D)$ Schematic representation of the conformation of $c$-Jun ARE unbound $(C)$ or bound by miR-200a $(D)$, predicted using RNAfold algorithm. Base pair probability is reported in a color scale. Modifier letter up arrowheads $(\wedge)$ show UGU triplet we have changed for GUC to generate miR-200a binding site mutant (MUT-A); plus signs (+) indicate $U \rightarrow$ A mutations that do not affect mRNA stability as reported by Peng et al. (1998); asterisks $\left(^{*}\right)$ indicate $\mathrm{G} \rightarrow \mathrm{C}$ mutations that increase mRNA stability as Vlasova et al. (2008) described.

see van Kouwenhove et al. 2011) so the action of of HuRmiRNP interactions can be different and also divergent, depending on the context such as cell types and cell status. There have been a few examples of miRNAs able to enhance the production of specific proteins. Most of the evidence comes from the work of Vasudevan and colleagues at the end of the past decade indicating a convincing direct relationship between the presence of specific miRNAs and the expression of a definite set of proteins. These noncanonical, positive effects of microRNAs seem to be delimited by a series 
of conditions, the most important being the growth condition (Vasudevan et al. 2007) and the stress status of the cells (Prislei et al. 2013).

In the experiments we present here, miR-200a and miR$200 \mathrm{~b}$ regulate the production of $c$-Jun in an opposite way: while mir-200b has an inhibitory effect on the translation of $c$-Jun mRNA and, notably, this effect is sufficient to prevent the migration of MDA-MB-231 cells in a scratch test; miR-200a, in concert with HuR, is able to stabilize c-Jun mRNA and, in turn, to increase the amount of JUN protein, AP1 transcription factor and some of the genes regulated by AP1. This noncanonical effect is not dependent on the specific miRNA, instead it seems to be dependent on the location of the binding site on c-Jun mRNA $3^{\prime} \mathrm{UTR}$. In fact, when the mir-200a site on the $3^{\prime} \mathrm{UTR}$ is mutated to recognize mir-200b, this microRNA is now able to stabilize the mRNA. Remarkably, the binding site of mir-200a is located inside the ARE recognized by HuR, so the action of the microRNA could be due to a direct influence on the structure of $c$-Jun $3^{\prime} \mathrm{UTR}$. This possibility seems to be supported by RNA folding predictions obtained through the utilization of "state of the art" algorithms (Fig. 4). With regard to this, it is important to notice that a fundamental feature able to determine the interplay between RBPs and miRNAs on target mRNAs is the structure and the sequence of the AREs present in the $3^{\prime}$ UTR. Different ARE-containing mRNAs respond in quite a different extent to changes in HuR activity (Peng et al. 1998). These differences probably reflect a different binding affinity of HuR for the ARE-containing mRNAs: the stronger the binding, the stronger the effect on the mRNA. However, this effect can be modulated: A study by Sharma and colleagues in 2013 indicates that the presence of a human microRNA, miR-3134, can affect the binding of HuR on a subset of human ARE bearing transcripts including Vegf, Sox9, and Egfr (Sharma et al. 2013). Our experiments suggest the intriguing possibility that a subclass of ARE-containing mRNAs are able to bind HuR with high efficiency only in the presence of miRNAs (and maybe other cofactors). In the case of the mir-200 family, different expression of members of the family could finely regulate the production of such an important oncogene like c-Jun.

Another condition possibly able to influence miRNA-HuR action on the target mRNAs is the structure of the miRNA binding sites. Bracken and colleagues performed a genomewide analysis of mRNAs targeted by mir- 200 family members in different cell lines (Bracken et al. 2014). The complex results obtained seem to indicate that while an $8 \mathrm{mer}$ binding site preferentially leads to an inhibition of translation and to a destabilization of the mRNA, the results are less clear when the binding site is a $7 \mathrm{mer}, 6 \mathrm{mer}$, or a $\mathrm{M}(\mathrm{is}) \mathrm{M}$ (atch) site. In our cases, while the miR-200b has an 8 mer binding site, miR-200a interacts through a 7 mer binding site; moreover, when the two sites are reversed, miR200-b is able to increase the production of $c$-Jun protein when interacting with the ARE of $c$-Jun $3^{\prime}$ UTR through a 7 mer site.
In conclusion, our findings elucidate an unexpected complex post-transcriptional regulation of $c$-Jun mRNA, based on the interplay between miR-200 family members and HuR RBP. This coordinated process opens new insights into the contribution of these factors to development, differentiation, and carcinogenesis.

\section{MATERIALS AND METHODS}

\section{Cell culture}

All cell lines (HEK 293T, HeLa, MCF7, MDA-MB-231) were cultured in D-MEM (PAA) supplemented with $10 \%$ fetal bovine serum (FBS, PAA) at $37^{\circ} \mathrm{C}$ with $5 \% \mathrm{CO}_{2}$.

\section{Plasmid construction}

To generate the constructs overexpressing miRNAs, the genomic fragments containing the pri-miR-200a or pri-miR-200b were PCR amplified and cloned using BglII and XhoI restriction sites of U1snRNA expression cassette (Denti et al. 2004).

The full-length $3^{\prime} \mathrm{UTR}$ sequence of $c$-Jun was amplified by PCR and then cloned in the XhoI restriction site of the psicheck-2 plasmid (Promega), downstream from the Renilla luciferase (RLuc) gene. The same plasmid also contains the Firefly luciferase (FLuc) to normalize transfection efficiency.

The 3'UTR sequences of Dusp1 were amplified by PCR and then directionally cloned in NotI and XhoI restriction sites of psicheck-2 plasmid.

Mutant derivatives of $c$-Jun $3^{\prime}$ UTR were obtained by generating partially complementary PCR fragments that were subsequently used as templates for PCR to generate complete mutated $3^{\prime}$ UTRs. They were, finally, cloned as described for the wild type. Specifically, MUT-A and MUT-B 3'UTRs were generated by replacement of three nucleotides of c-Jun $3^{\prime}$ UTR pairing from the second to the fourth nt of miR-200 seeds with 5'-GUC-3' (Fig. 1B, right panel); MUT-INV $3^{\prime}$ UTR presented the position of miR-200a and miR-200b binding sites reciprocally exchanged in the c-Jun $3^{\prime} \mathrm{UTR}$ (Fig. 3A). The compensatory seed mutation (ACA $\rightarrow$ GAC) in the miR-200a overexpressing plasmid was performed to restore the interaction with MUT-A 3'UTR.

All the sequences of the resulting vectors were verified by sequence analysis. Oligonucleotides used for cloning are listed in Supplemental Table I.

\section{Transfection and reporter assays}

For reporter assays, $1 \times 10^{5}$ HEK $293 \mathrm{~T}$ cells or $8 \times 10^{4} \mathrm{HeLa}$ cells were plated in 24-well plates and cotransfected with $100 \mathrm{ng}$ of $c^{-}$ Jun 3'UTR reporter plasmid (c-Jun 3'UTR, MUT-A 3'UTR, MUT-B 3'UTR, MUT-INV 3'UTR, or DUSP1 3'UTR) and $900 \mathrm{ng}$ of miR-200a or miR-200b overexpressing plasmid using Lipofectamine 2000 (Invitrogen). Twenty-four hours after transfection, the cells were lysed in Passive Lysis Buffer (Promega), and the luciferase activity was measured with the Dual-Luciferase Reporter Assay System (Promega) using the GloMax Multi Detection System Luminometer (Promega). All reporter assays were shown 
as relative luciferase activity (averaged ratios of RLuc/FLuc) and combined from at least three separate experiments.

For the experiments on endogenous $c$-Jun, cells were transfected at $80 \%$ confluency with microRNA overexpressing plasmids as previously described. Cells were harvested $24 \mathrm{~h}$ after the plasmids transfections for downstream processing.

HEK293T cells, $24 \mathrm{~h}$ after transfection with microRNA overexpressing plasmids, were treated with actinomycin $\mathrm{D}(10 \mu \mathrm{g} / \mathrm{mL}$, Sigma) for 2, 4, and $8 \mathrm{~h}$ to inhibit transcription. Cells were harvested after treatment for downstream processing.

For siRNA experiments, cells were transfected with $30 \mathrm{nM}$ control or HuR (Dharmacon) siRNAs, and in some cases after $24 \mathrm{~h}$ the cells were also cotransfected with reporter construct and microRNA overexpressing plasmids, as previously described. Cells were harvested $48 \mathrm{~h}$ after the siRNAs transfections for downstream processing.

For the experiments with LNA microRNA inhibitor, cells were transfected with $30 \mathrm{nM}$ of LNA inhibitor scramble, anti-miR200a, anti-miR-200b (miRCURY LNA microRNA inhibitor, Exiqon), and $24 \mathrm{~h}$ after transfection, the cells were lysed and processed as previously described.

\section{Quantitative real-time PCR}

Total RNA was isolated using the miRNeasy Mini Kit according to manufacturer's instructions (QIAGEN). cDNA generation was carried out using the miScript Reverse Transcription Kit (QIAGEN). The real-time PCR detection of mRNAs was performed using miScript SYBR-Green PCR Kit and DNA oligonucleotides by QIAGEN, on a 7300 Real-Time PCR (Applied Biosystems). The values obtained were normalized for Gapdh and analyzed by the unpaired Student's $t$-test. Relative quantification was performed using the comparative cycle threshold $(\Delta \Delta \mathrm{Ct})$ method. $P$-values were calculated for samples from at least three independent experiments unless otherwise indicated.

\section{Western blotting}

Whole-cell protein extracts were prepared from cells lysed in RIPA buffer. Proteins were resolved by $12 \%$ SDS-PAGE and transferred onto nitrocellulose membrane (Whatman, Schleicher \& Schuell). The immunoblots were incubated with the following antibodies: anti-actin (A2066, Sigma-Aldrich), anti-JUN (ab31415, Abcam). The densitometric analysis was performed using Image Lab software (Bio-Rad).

\section{Wound healing assay}

Of note, $5 \times 10^{5}$ MDA-MB-231 cells were plated in the uncoated microslide two well (ibidi) and transfected with 2 ug of miR-200a or miR-200b overexpressing plasmid or with $30 \mathrm{nM}$ of $c$-Jun (Dharmacon) siRNAs, using Lipofectamine 2000 (Invitrogen). Twenty-four hours after transfection the cell monolayer was scraped in a straight line with a p200 pipette tip. The time-lapse imaging of living cells was acquired with a Nikon Eclipse Ti inverted microscope hourly for $24 \mathrm{~h}$.

\section{RNA IP assays}

RIP was performed by incubating 20 ug of antibody anti-HuR (sc5261; Santa Cruz) or isotypic IgG (12-371, Millipore) to $30 \mathrm{~mL}$ of
Protein A/G salmon sperm agarose beads (Millipore) for $2 \mathrm{~h}$ at $4^{\circ} \mathrm{C}$. HEK $293 \mathrm{~T}$ cytoplasmatic lysates were prepared from cells cultured in complete medium for $24 \mathrm{~h}$, after microRNA overexpressing plasmid transfection, with $100 \mathrm{~mL}$ of passive lysis buffer (PLB). Two hundred milligrams of each lysate was used for each RIP assay. Samples were precleared for $1 \mathrm{~h}$ at $4^{\circ} \mathrm{C}$ with $30 \mathrm{~mL}$ of beads, and the supernatant was then resuspended in $600 \mathrm{~mL}$ of NT2 buffer and added to antibody-coated beads for $4 \mathrm{~h}$ at $4^{\circ} \mathrm{C}$. The beads were washed with NT2 buffer five times and split for protein (one-third) and RNA analysis (two-thirds). One-fifth of the input lysate was used as control. PLB and NT2 buffers were prepared according to Tenenbaum et al. (2002).

\section{Secondary structure predictions}

The secondary structure prediction of c-Jun ARE and the comparison between the structures of the "unbound state" and of the "miR200a-bound state" were performed by using RNAfold (Vienna RNA package). In addition to the minimum free energy (mfe) (Stiegler et al. 1981), the partition function (pf) base pair probabilities in the thermodynamic ensemble were calculated (McCaskill 1990). Turner energy parameters from 2004 were used. The probability of a base pair sort was calculated by counting the number of structures in the whole ensemble of all possible structures that include that particular base pair and the weight of each structure by its free energy. This sum is then normalized by the ensemble of all possible structures, regardless of whether they include that base pair or not. To get the secondary structure of 152-nt-long c-Jun ARE by RNAfold, the sequence was cut out of the $3^{\prime}$-UTR manually and was folded separately. According to Lange et al. (2012), RNAfold is only accurate for short sequences (max $150 \mathrm{nt}$ ) and RNAplfold is the preferred method for long sequences twofold folding prediction. Thus, RNAplfold was used to take into account the influence of the context sequence and to check the structure calculated with RNAfold. Both algorithms gave similar results.

\section{SUPPLEMENTAL MATERIAL}

Supplemental material is available for this article.

\section{ACKNOWLEDGMENTS}

Live-cell imaging experiments were performed at the Nikon Reference Centre, CNR Institute of Molecular Biology and Pathology. We acknowledge Giulia Guarguaglini for guidance and support. We thank Bio-Fab Research for helpful technical support. We thank Mariangela Sociale and Maria Cristina Capizzi, former students in the laboratory, for their contribution in constructing the clones. This work was supported by Project F57I12000110009 Filas Regional Grant to C.P., ERC-2013 (AdG 340172-MUNCODD), EpigenEpigenomics Flagship Project, HFSP (RGP0009/2014) to I.B.

Author contributions: F.D.V. and G.D.V. designed and performed most of the experiments, analyzed data, interpreted results, and participated in manuscript writing; A.R. and C.M. performed clone construction and in silico analysis; S.J.S. performed 2D-RNA folding analysis; I.B. oversaw the project; and C.P. designed experiments, analyzed, and interpreted results and wrote the manuscript.

Received May 19, 2016; accepted May 27, 2016. 


\section{REFERENCES}

Abdelmohsen K, Gorospe M. 2010. Posttranscriptional regulation of cancer traits. Wiley Interdiscip Rev RNA 1: 214-229.

Bousquet-Antonelli C, Presutti C, Tollervey D. 2000. Identification of a regulated pathway for nuclear pre-mRNA turnover. Cell 102: $765-775$.

Bracken CP, Li X, Wright JA, Lawrence DM, Pillman KA, Salmanidis M, Anderson MA, Dredge BK, Gregory PA, Tsykin A, et al. 2014. Genome-wide identification of miR-200 targets reveals a regulatory network controlling cell invasion. EMBO J 33: 2040-2056.

Chu CH, Chou W, Wang F, Yeh CN, Chen TC, Yeh TS. 2015. Expression profile of microRNA-200 family in cholangiocarcinoma arising from choledochal cyst. J Gastroenterol Hepatol 31: 1052-1059.

Denti MA, Rosa A, Sthandier O, De Angelis FG, Bozzoni I. 2004. A new vector, based on the Pol II promoter of the U1 snRNA gene, for the expression of siRNAs in mammalian cells. Mol Ther 10: 191-199.

Ghosh M, Aguila HL, Michaud J, Ai Y, Wu MT, Hemmes A, Ristimaki A, Guo C, Furneaux H, Hla T. 2009. Essential role of the RNA-binding protein HuR in progenitor cell survival in mice. J Clin Invest 119: 3530-3543.

Ha M, Kim VN. 2014. Regulation of microRNA biogenesis. Nat Rev Mol Cell Biol 8: 509-524.

Hinman MN, Lou H. 2008. Diverse molecular functions of Hu proteins. Cell Mol Life Sci 65: 3168-3181.

Jadhav SP, Kamath SP, Choolani M, Lu J, Dheen ST. 2014. microRNA$200 \mathrm{~b}$ modulates microglia-mediated neuroinflammation via the cJun/MAPK pathway. J Neurochem 130: 388-401.

Jain RG, Andrews LG, McGowan KM, Pekala PH, Keene JD. 1997. Ectopic expression of Hel-N1, an RNA-binding protein, increases glucose transporter (GLUT1) expression in 3T3-L1 adipocytes. Mol Cell Biol 17: 954-962.

Keene JD. 1999. Why is Hu where? Shuttling of early-response-gene messenger RNA subsets. Proc Natl Acad Sci 96: 5-7.

Keene JD. 2007. RNA regulons: coordination of post-transcriptional events. Nat Rev Genet 8: 533-543.

Kim HH, Kuwano Y, Srikantan S, Lee EK, Martindale JL, Gorospe M. 2009. HuR recruits let-7/RISC to repress c-Myc expression. Genes Dev 23: 1743-1748.

Korpal M1, Lee ES, Hu G, Kang Y. 2008. The miR-200 family inhibits epithelial-mesenchymal transition and cancer cell migration by direct targeting of E-cadherin transcriptional repressors ZEB1 and ZEB2. J Biol Chem 283: 14910-14914.

Kozomara A, Griffiths-Jones S. 2014. miRBase: annotating high confidence microRNAs using deep sequencing data. Nucleic Acids Res 42: $68-73$

Kullmann M, Göpfert U, Siewe B, Hengst L. 2002. ELAV/Hu proteins inhibit p27 translation via an IRES element in the p27 $5^{\prime}$ UTR. Genes Dev 16: 3087-3099.

Kuwano Y, Kim HH, Abdelmohsen K, Pullmann R Jr, Martindale JL, Yang X, Gorospe M. 2008. MKP-1 mRNA stabilization and translational control by RNA-binding proteins HuR and NF90. Mol Cell Biol 28: 4562-4575.

Lange SJ, Maticzka D, Möhl M, Gagnon JN, Brown CM, Backofen R. 2012. Global or local? Predicting secondary structure and accessibility in mRNAs. Nucleic Acids Res 40: 5215-5226.

Lebedeva S, Jens $M$, Theil $K$, Schwanhäusser B, Selbach $M$, Landthaler M, Rajewsky N. 2011. Transcriptome-wide analysis of regulatory interactions of the RNA-binding protein HuR. Mol Cell 43: 340-352.

Levadoux-Martin M, Gouble A, Jégou B, Vallet-Erdtmann V, Auriol J, Mercier P, Morello D. 2003. Impaired gametogenesis in mice that over express the RNA-binding protein HuR. EMBO Rep 4: 394-399.
Lopez-Bergami P, Lau E, Ze'ev R. 2010. Emerging roles of ATF2 and the dynamic AP1 network in cancer. Nat Rev Cancer 10: 65-76.

Lu YC, Chang SH, Hafner M, Li X, Tuschl T, Elemento O, Hla T. 2014. ELAVL1 modulates transcriptome-wide miRNA binding in murine macrophages. Cell Rep 9: 2330-2343.

McCaskill JS. 1990. The equilibrium partition function and base pair binding probabilities for RNA secondary structure. Biopolymers 29: 1105-1119.

Mitchell P, Tollervey D. 2000. mRNA stability in eukaryotes. Curr Opin Genet Dev 10: 193-198.

Mukherjee N, Corcoran DL, Nusbaum JD, Reid DW, Georgiev S, Hafner M, Ascano M Jr, Tuschl T, Ohler U, Keene JD. 2011. Integrative regulatory mapping indicates that the RNA-binding protein HuR couples pre-mRNA processing and mRNA stability. Mol Cell 43: 327-339.

Orphanides G, Reinberg D. 2000. A unified theory of gene expression. Cell 108: 439-451.

Park SM, Gaur AB, Lengyel E, Peter ME. 2008. The miR-200 family determines the epithelial phenotype of cancer cells by targeting the Ecadherin repressors ZEB1 and ZEB2. Genes Dev 22: 894-907.

Peng SS, Chen CY, Xu N, Shyu AB. 1998. RNA stabilization by the AUrich element binding protein, HuR, an ELAV protein. EMBO J 17: 3461-3470.

Prislei S, Martinelli E, Mariani M, Raspaglio G, Sieber S, Ferrandina G, Shahabi S, Scambia G, Ferlini C. 2013. MiR-200c and HuR in ovarian cancer. BMC Cancer 8: 13-72.

Sharma S, Verma S, Vasudevan M, Samanta S, Thakur JK, Kulshreshtha R. 2013. The interplay of HuR and miR-3134 in regulation of AU rich transcriptome. RNA Biol 10: 1283-1290.

Simone LE, Keene JD. 2013. Mechanisms coordinating ELAV/Hu mRNA regulons. Curr Opin Genet Dev 23: 35-43.

Stiegler P, Carbon P, Zuker M, Ebel JP, Ehresmann C. 1981. Structural organization of the $16 \mathrm{~S}$ ribosomal RNA from E. coli. Topography and secondary structure. Nucleic Acids Res 9: 2153-2172.

Tenenbaum SA, Lager PJ, Carson CC, Keene JD. 2002. Ribonomics: identifying mRNA subsets in mRNP complexes using antibodies to RNA-binding proteins and genomic arrays. Methods 26: 191198.

van Kouwenhove M, Kedde M, Agami R. 2011. MicroRNA regulation by RNA-binding proteins and its implications for cancer. Nat Rev Cancer 11: 644-656.

Vasudevan S, Tong Y, Steitz JA. 2007. Switching from repression to activation: microRNAs can up-regulate translation. Science 318: 1931-1934.

Vlasova IA, Tahoe NM, Fan D, Larsson O, Rattenbacher B, Sternjohn JR, Vasdewani J, Karypis G, Reilly CS, Bitterman PB, et al. 2008. Conserved GU-rich elements mediate mRNA decay by binding to CUG-binding protein 1. Mol Cell 29: 263-270.

Wang J, Guo Y, Chu H, Guan Y, Bi J, Wang B. 2013. Multiple functions of the RNA-binding protein HuR in cancer progression, treatment responses and prognosis. Int J Mol Sci 14: 10015-10041.

Yeh CH, Hung LY, Hsu C, Le SY, Lee PT, Liao WL, Lin YT, Chang WC, Tseng JT. 2008. RNA-binding protein HuR interacts with thrombomodulin $5^{\prime}$ untranslated region and represses internal ribosome entry site-mediated translation under IL-1 $\beta$ treatment. Mol Biol Cell 19: 3812-3822.

Zhang J, Modi Y, Yarovinsky T, Yu J, Collinge M, Kyriakides T, Zhu Y, Sessa WC, Pardi R, Bender JR. 2012. Macrophage $\beta 2$ integrinmediated, HuR-dependent stabilization of angiogenic factorencoding mRNAs in inflammatory angiogenesis. Am J Pathol 180: $1751-1760$. 

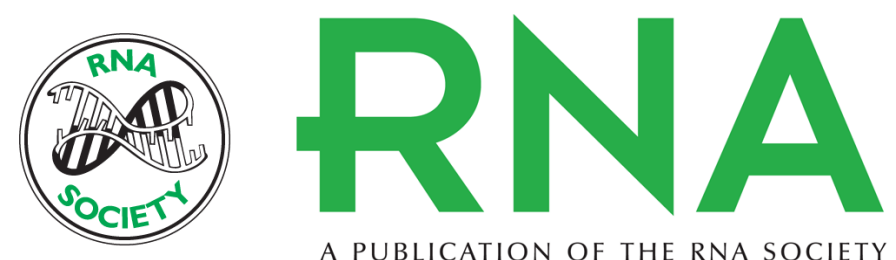

A PUBLICATION OF THE RNA SOCIETY

\section{RNA-binding protein HuR and the members of the miR-200 family play an unconventional role in the regulation of $c$-Jun mRNA}

Giorgia Del Vecchio, Francesca De Vito, Sita J. Saunders, et al.

RNA 2016 22: 1510-1521 originally published online July 29, 2016

Access the most recent version at doi:10.1261/rna.057588.116

\section{Supplemental http://rnajournal.cshlp.org/content/suppl/2016/07/29/rna.057588.116.DC1 Material}

References This article cites 39 articles, 12 of which can be accessed free at: http://rnajournal.cshlp.org/content/22/10/1510.full.html\#ref-list-1

Creative This article is distributed exclusively by the RNA Society for the first 12 months after the Commons License full-issue publication date (see http://rnajournal.cshlp.org/site/misc/terms.xhtml). After 12 months, it is available under a Creative Commons License (Attribution-NonCommercial 4.0 International), as described at http://creativecommons.org/licenses/by-nc/4.0/.
Email Alerting Receive free email alerts when new articles cite this article - sign up in the box at the Service top right corner of the article or click here.

To subscribe to $R N A$ go to:

http://rnajournal.cshlp.org/subscriptions 